\title{
FEMINICÍDIO DURANTE A PANDEMIA DA COVID-19
}

\section{FEMINICIDE DURING THE COVID-19 PANDEMIC}

\section{FEMINICIDIO DURANTE LA PANDEMIA DEL COVID-19}

\author{
Rosario Martinho Sunde \\ Lucildina Muzuri Conferso Sunde ${ }^{2}$ \\ Larissa Fenalte Esteves ${ }^{3}$
}

\begin{abstract}
Resumo
Este é um artigo de Revisão Sistemática, com o objetivo de avaliar o índice de mulheres vítimas de feminicídio no período da pandemia da COVID-19. A busca de dados ocorreu durante o mês de junho de 2020, em 5 bases de dados (LILACS, SciElo, Science Direct, MEDLINE e Psyclnfo) por meio de PRISMA. Foram achados, inicialmente, cerca de 951 artigos, dos quais 9 foram usados para a análise final. Concluiu-se que o índice de feminicídio aumentou consideravelmente durante esse período em relação aos meses anteriores, devido ao isolamento social. Este fator impossibilita que as vítimas consigam sair de casa e a nova rotina dentro de casa coabitando com o agressor vulnerabiliza sua vida. Sugere-se, assim, que se promova políticas de divulgação de leis e princípios dos direitos humanos e de violência contra mulheres, sensibilizando as vítimas e pessoas próximas a denunciar os agressores.
\end{abstract}

Palavras-chave: Feminicídio. Mulher. Pandemia. COVID-19.

\begin{abstract}
This is a Systematic Review article, with the objective of evaluating the index of women victims of femicide during the COVID-19 pandemic period. The data search occurred during the month of June 2020, in 5 databases (LILACS, SciElo, Science Direct, MEDLINE and Psyclnfo) through PRISMA. Initially, 951 articles were found, of which 9 were used for the final analysis. It was concluded that the rate of femicide increased considerably during this period in relation to the previous months, due to social isolation. This factor makes it impossible for victims to be able to leave the house and the new routine inside the home cohabiting with the aggressor makes their life vulnerable. It is suggested, therefore, that policies be promoted to disseminate laws and principles of human rights and violence against women, sensitizing victims and people close to denouncing aggressors.
\end{abstract}

Keywords: Feminicide. Woman. Pandemic. COVID-19.

\section{Resumen}

Este es un artículo de Revisión Sistemática, con el objetivo de evaluar el índice de mujeres víctimas de feminicidio

${ }^{1}$ Doutorando em Psicologia Clínica na Pontifícia Universidade Católica do Rio Grande do Sul - PUCRS. Membro do

de Pesquisa-Avaliação em Bem-Estar e Saúde Mental. Bolsista CAPES-Brasil (2018). Graduado em Psicologia Escolar pela Universidade Pedagógica Nampula (2008) e mestrado em Administração e Gestão Escolar pela Universidade Pedagógica-Nampula (2015). Docente da Universidade Rovuma - UniRovuma - Moçambique. Email: rsundescanda@gmail.com. ORCID https://orcid.org/0000-0001-5906-3856.

2 Mestranda do Programa de Pós-graduação em Saúde Coletiva da Escola de Enfermagem da Universidade Federal do Rio Grande do Sul (UFRGS)- Brasil, docente do Centro de Educação Inclusiva Josina Machel de Nampula- Moçambique, graduada em Psicologia Escolar pela Universidade Pedagógica de Moçambique. E-mail: lucildinaconferso@gmail.com. ORCID https://orcid.org/0000-0002-4853-5552

${ }^{3}$ Aluno de Graduação do Curso de Psicologia da Pontifícia Universidade Católica do Rio Grande do Sul (PUCRS) - Brasil. Membro do Grupo de Pesquisa-Avaliação em Bem-Estar e Saúde Mental no Programa de Pós-graduação da PUCRS. E-mail: larissafenalte@gmail.com. ORCID https://orcid.org/0000-0002-0185-5508. 
durante el período de la pandemia COVID-19. La búsqueda de datos se realizó durante el mes de junio de 2020, en 5 bases de datos (LILACS, SciElo, Science Direct, MEDLINE y Psyclnfo) a través de PRISMA. Inicialmente se encontraron 951 artículos, de los cuales 9 se utilizaron para el análisis final. Se concluyó que la tasa de feminicidios aumentó considerablemente durante este período en relación a los meses anteriores, debido al aislamiento social. Este factor imposibilita que las víctimas puedan salir de casa y la nueva rutina dentro del hogar de convivencia con el agresor hace que su vida sea vulnerable. Se sugiere, por tanto, que se impulsen políticas de difusión de leyes y principios de derechos humanos y violencia contra las mujeres, sensibilizando a las víctimas y personas cercanas a la denuncia de los agresores.

Palabras clave: Feminicidio. Mujer. Pandemia. COVID-19.

\section{INTRODUÇÃO}

O feminicídio é o assassinato de mulheres cometidos em razão do gênero, ou seja, quando a vítima é morta por ser mulher. É um crime de ódio baseado no gênero que vem se registrando durante muito tempo cujos praticantes, em sua maioria, são ex-companheiros ou os atuais esposos das vítimas. No Brasil, isso se reflete nos estados de São Paulo e Rio de Janeiro, destacando o Rio de Janeiro com um aumento considerável de 50\% em casos de violência doméstica nos últimos dias, por conta do isolamento social (LEITE, 2020).

Por isso, na primeira atualização de um relatório produzido a pedido do Banco Mundial, o Fórum Brasileiro de Segurança Pública destaca a prevalência de casos de feminicídios que cresceu 22,2\% entre março e abril de 2020 em 12 estados do país, comparativamente ao ano passado. Segundo o relatório, o estado em que se observa o agravamento mais crítico é o Acre, onde o aumento foi de $300 \%$. Na região, o total de casos passou de um para quatro ao longo do bimestre. Também tiveram destaque negativo o Maranhão, com variação de 6 para 16 vítimas (166,7\%), e Mato Grosso, que iniciou o bimestre com 6 vítimas e o encerrou com 15 (150\%) (AGÊNCIA BRASIL, 2020).

O termo feminicídio foi utilizado pela primeira vez em sessões do Primeiro Tribunal Internacional de Crimes contra as Mulheres, em Bruxelas, na Bélgica, em 1976. Neste tribunal sobre mortes de mulheres nos Estados Unidos e no Líbano, a ativista feminista Diana Russell testemunhou e defendeu que tais ocorrências seriam consequência de ações misóginas e, como tal, deveriam ser apresentadas e julgadas seriamente como feminicídios (ROMIO, 2017).

No Brasil, o feminicídio é um crime previsto no Código Penal, incluído na legislação através da Lei ํㅜ 13.104, de 2015 inciso VI, $\S 2^{\circ}$, do artigo 121, quando cometido "contra a mulher por razões da condição de sexo feminino". O §-A, do artigo 121, do referido código, complementa o inciso já citado ao estabelecer que há razões de condição de sexo feminino 
quando o crime envolver: I - violência doméstica e familiar (o artigo 5o da Lei nำ 11.340/06 enumera o que é considerado pela lei violência doméstica); II - menosprezo ou discriminação à condição de mulher (BRASIL, 2015).

Estudos indicam que a taxa de feminicídios no Brasil chega a 4,8 casos a cada 100 mil mulheres, colocando o país na 5a posição dos países com maior incidência de casos no mundo e, durante o período entre 1980 e 2013 ocorreram cerca de 106.093 assassinatos de motivação misógina (BRASIL, 2018). Segundo a AGÊNCIA BRASIL (2020), no estado de São Paulo, em 2019, a cada 10 vítimas de feminicídio, 7 foram assassinadas dentro de casa. Um total de 125 mortes ocorreram nas residências das vítimas no ano passado, o que representa um aumento de $40 \%$ em relação a 2018, em que ocorreram 89 mortes em casa. 0 levantamento foi revelado pelo Instituto Sou da Paz, com base nos números disponibilizados pela Secretaria de Segurança Pública do estado e Corregedorias das Polícias Civil e Militar. A fonte sustenta, ainda, que em $80 \%$ dos casos a vítima conhecia o autor do feminicídio (AGÊNCIA BRASIL, 2020).

Com a pandemia da COVID-19 e o risco de agressores coabitarem junto às vítimas, espera-se que os casos de violência doméstica e feminicídio aumentem, como se descreve em um estudo de Maranhão (2020) destacando um aumento de notificações de casos de violências domésticas durante a quarentena publicadas em redes nacionais e internacionais, com maior prevalência na China, Itália, Reino Unido, França, Dinamarca, Argentina e Espanha.

Os estudos apresentados constituem uma parte dos casos de mulheres vítimas de feminicídio, não contabilizando tantos outros sem registro e muito menos conhecidos. Este artigo visa avaliar o índice de mulheres vítimas de feminicídio no período da pandemia da COVID-19. Esperamos, com esse estudo, contribuir para a divulgação dos direitos humanos, protegendo as mulheres, encorajando a população a denunciar e repudiar este macabro crime.

\section{MÉTODO}

A presente Revisão foi conduzida por meio de Preferred Reporting Items for Systematic Reviews and Meta-Analyses (PRISMA). A busca dos artigos foi feita em junho de 2020, nas seguintes bases: LILACS; SciElo; Science Direct; MEDLINE e Psyclnfo usando as seguintes palavras-chave (Feminicide AND Quarantine AND COVID-19 OR Coronavirus; Feminicide OR Violence AND Quarantine AND COVID-19 e Feminicide AND COVID-19 OR Coronavirus). 
Depois da busca, os artigos foram exportados para o "Rayyan QCRl" (aplicativo web/móvel gratuito que auxilia autores de Revisão Sistemática a realizar o processo de seleção dos artigos de forma rápida e eficiente). Foi com este programa (Rayyan QCRI) que executamos todas as atividades, desde a identificação, triagem, inclusão e exclusão de artigos duplicados, estudos sem relação com a nossa pesquisa e a comunicação entre os avaliadores (OLOFSSON et al., 2017; OUZZANI, HAMMADY, FEDOROWICZ, ELMAGARMID, 2016). O processo de seleção dos artigos foi realizado de forma independente inicialmente por 2 avaliadores, tendo recorrido a uma terceira pessoa para solucionar casos inconsistentes.

Foram usados como critérios para a inclusão dos artigos aqueles que discutem a temática do feminicídio durante a pandemia da COVID-19. No entanto, para avaliar a evolução do fenômeno, foram contemplados estudos desenvolvidos nos últimos 5 anos. E utilizou-se como critério de exclusão os artigos repetidos. Foram encontrados, inicialmente 951 estudos que, depois de exclusão por estarem duplicados (17), procedeu-se à leitura dos títulos e dos resumos num total de 934 artigos, cujos 37 atenderam aos critérios de inclusão e foram lidos na íntegra; destes, foram excluídos ainda, 28 artigos com temas incompatíveis (27) e com resultados incongruentes (1), restando 9, que foram usados para análise final. A Figura1 ilustra como foi o processo de busca e tratamento dos artigos.

Figura 1: Fluxograma da seleção dos artigos

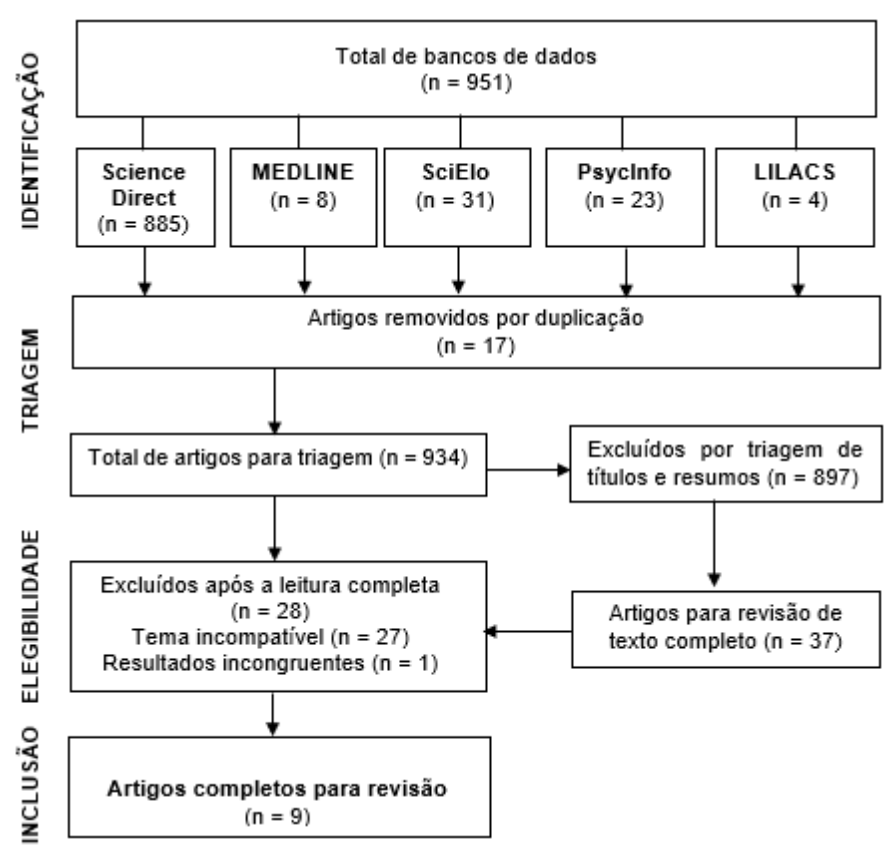




\section{RESULTADOS}

A Tabela 1 descreve os estudos usados na análise. Nela consta método e objetivo de cada pesquisa, situações associadas ao feminicídio e resultados alcançados. Na generalidade, os estudos foram desenvolvidos a partir de revisões de literatura. No entanto, entre os estudos achados (9), somente um faz análise das medidas de contenção da violência durante a pandemia da COVID-19. Isto não significa que não haja registro de casos neste período, talvez por ser uma realidade recente e menos explorada.

Tabela 1. Síntese dos artigos incluídos

\begin{tabular}{|c|c|c|c|c|}
\hline $\mathrm{Nr}$ & Referências & Método & Objetivo & $\begin{array}{l}\text { Situações } \\
\text { associados ao } \\
\text { feminicídio }\end{array}$ \\
\hline $\begin{array}{l}\text { Artigo } \\
1\end{array}$ & $\begin{array}{l}\text { VANEGAS } \\
\text { (2015). }\end{array}$ & $\begin{array}{l}\text { Revisão } \\
\text { (Colômbia) }\end{array}$ & $\begin{array}{l}\text { Analisar } \\
\text { feminicídio } \\
\text { dentro de um } \\
\text { contexto mais } \\
\text { amplo da } \\
\text { violência contra } \\
\text { a mulher. }\end{array}$ & $\begin{array}{l}\text { Violência contra } \\
\text { a mulher } \\
\text { (doméstica, } \\
\text { sexual, física, } \\
\text { psicológica, } \\
\text { econômica } \\
\text { patrimonial, } \\
\text { estrutural } \\
\text { institucional). } \\
\text { - Relação de } \\
\text { subordinação e } \\
\text { dominação } \\
\text { - Prostituição } \\
\text { forçada } \\
\text { - Entre casais: } \\
\text { objetificação do } \\
\text { corpo e vida da } \\
\text { mulher } \\
\text { - Impunidade } \\
\text { gerada } \\
\text { Estado. pelo } \\
\text { - Ciúme } \\
\text { - Discriminacão }\end{array}$ \\
\hline
\end{tabular}

\section{Resultados da pesquisa}

A violência contra as mulheres é um conceito amplo que não pode ser reduzido à violência sexual e nem pode ser confundido com feminicídio. Esse é 0 ato extremo de violência, mas no meio encontramos outras formas, como a violência simbólica, estrutural e econômica. Na Colômbia o feminicídio foi tipificado no artigo 26 da Lei 1257 de 2008, mas somente até 4 de março de 2015 o Supremo Tribunal de Justiça emitiu sentença que lançou as bases para o entendimento da conduta $e$ a configuração com toda a seriedade. Ao contrário do que foi afirmado no julgamento de segunda instância analisado, o ciúme não constitui um ato passional, mas faz parte do padrão de dominação e, portanto, não pode ser reconhecido como atenuante, mas agravante. Foi percorrido um longo caminho para uma verdadeira igualdade entre homens e mulheres, mas ainda há um longo caminho a percorrer para eliminar a violência e a discriminação. Segundo dados do Centro de Estudos

\begin{tabular}{|c|c|c|c|c|c|}
\hline $\begin{array}{l}\text { Artigo } \\
2\end{array}$ & $\begin{array}{l}\text { ALBARRAN } \\
\text { (2015). }\end{array}$ & $\begin{array}{l}\text { Revisão } \\
\text { (Venezuela) }\end{array}$ & $\begin{array}{l}\text { Apresentar } \\
\text { diferentes } \\
\text { concepções } \\
\text { feminicídio } \\
\text { examinar } \\
\text { diferentes } \\
\text { interesses }\end{array}$ & de & $\begin{array}{l}\text {-Tolerância } \\
\text { social em } \\
\text { relação à } \\
\text { violência contra } \\
\text { as mulheres. } \\
\text {-Impunidade } \\
\text { praticamente }\end{array}$ \\
\hline
\end{tabular}
da Mulher na Venezuela, 60 feminicídios foram registrados no primeiro semestre de 2014. Atualmente, a imprensa relata pelo menos uma mulher morta semanalmente. $O$ desenvolvimento 


\begin{tabular}{|c|c|c|c|c|c|}
\hline & & & $\begin{array}{l}\text { perspectivas } \\
\text { teóricas. }\end{array}$ & $\begin{array}{l}\text { generalizada. } \\
\text {-Falta de } \\
\text { vontade política } \\
\text { para enfrentar } \\
\text { específica e } \\
\text { adequadamente } \\
\text { a violência } \\
\text { contra ex } \\
\text { mulheres. } \\
\text { - Supremacia } \\
\text { masculina. } \\
\text {-Ato passional } \\
\text { (esposo, } \\
\text { esposo, } \\
\text { namorado } \\
\text { relacionamento } \\
\text { casal } \\
\text { conturbado). } \\
\text { - Poder, controle } \\
\text { e dominação de } \\
\text { homens sobre } \\
\text { mulheres } \\
\text { - Violência } \\
\text { sexual }\end{array}$ & $\begin{array}{l}\text { conceitual do assunto ainda é } \\
\text { incipiente na Venezuela. Sem dúvida, } \\
\text { o debate social e político sobre a } \\
\text { relevância da criminalização desse } \\
\text { crime na legislação venezuelana é de } \\
\text { grande importância, desde que não } \\
\text { se desvie a atenção de outras } \\
\text { obrigações que o Estado tem para } \\
\text { garantir os direitos das mulheres para } \\
\text { uma vida livre de violência e do } \\
\text { feminicídio. }\end{array}$ \\
\hline $\begin{array}{l}\text { Artigo } \\
3\end{array}$ & $\begin{array}{l}\text { SOUSA } \\
(2016) .\end{array}$ & $\begin{array}{l}\text { Revisão } \\
\text { (Brasil) }\end{array}$ & $\begin{array}{lr}\text { Formular } & \text { um } \\
\text { olhar sobre } & \text { o } \\
\text { fenômeno } & \text { do } \\
\text { feminicídio } & \text { a } \\
\text { partir } & \text { das } \\
\text { categorias } & \text { de } \\
\text { análise } & \text { da } \\
\text { diferença } & \text { e } \\
\text { hierarquia, } & \\
\text { entendidas } & \text { no } \\
\text { âmbito } & \text { dos } \\
\text { estudos } & \\
\text { feministas. } & \end{array}$ & $\begin{array}{l}\text {-Ameaçam a da } \\
\text { dignidade } \\
\text { mulher } \\
\text {-Prática } \\
\text { extermínio } \\
\text { seletivo, } \\
\text { desaparecimento } \\
\text { ou rapto, com } \\
\text { tortura, violação } \\
\text { sexual, quase } \\
\text { sempre seguida } \\
\text { de morte, de } \\
\text { mulheres jovens, } \\
\text { trabalhadoras e } \\
\text { pobres, } \\
\text { submissão, } \\
\text { escravidão, } \\
\text { exploração } \\
\text { sexual, } \\
\text { mutilação } \\
\text { sexual. } \\
\text {-Violência } \\
\text { associada } \\
\text { contextos a } \\
\text { generalizados de } \\
\text { ódio e de } \\
\text { discriminação } \\
\text { sobre } \\
\text { mulheres. }\end{array}$ & $\begin{array}{l}\text { O conjunto de noções, produzidas no } \\
\text { âmbito dos estudos feministas, ainda } \\
\text { que tenham vindo a constituir-se } \\
\text { como alertas e esclarecimentos } \\
\text { relevantes que informam a agenda } \\
\text { política, não têm tido capilaridade } \\
\text { decisiva nas representações sociais, } \\
\text { tanto no empoderamento das } \\
\text { mulheres de se colocarem como } \\
\text { sujeitos de direitos, como na reversão } \\
\text { dos valores assimilados pelos } \\
\text { homens, sobretudo no âmbito das } \\
\text { relações familiares. Tal constatação } \\
\text { evidencia-se, por exemplo, nos } \\
\text { desdobramentos da Lei Maria da } \\
\text { Penha, que, poucos anos após a sua } \\
\text { aplicação, não conseguiu colocar-se } \\
\text { como mudança de paradigma a partir } \\
\text { dos valores das lutas feministas e dos } \\
\text { direitos humanos. As iniciativas } \\
\text { legislativas que ocorrem ao redor do } \\
\text { mundo têm compreendido aquela } \\
\text { diferença imposta pela hierarquia } \\
\text { como um fator determinante da } \\
\text { discriminação e das práticas de } \\
\text { submissão violenta da mulher. }\end{array}$ \\
\hline
\end{tabular}




\begin{tabular}{|c|c|c|c|c|c|}
\hline $\begin{array}{l}\text { Artigo } \\
4\end{array}$ & $\begin{array}{l}\text { OLIDEN; } \\
\text { VELÁSQUEZ } \\
\text { (2017). }\end{array}$ & $\begin{array}{l}\text { Estudo de } \\
\text { caso } \\
\text { (Bolívia) }\end{array}$ & $\begin{array}{l}\text { Analisar um } \\
\text { dos fenômenos } \\
\text { mais } \\
\text { controversos e } \\
\text { importantes do } \\
\text { nosso } \\
\text { ambiente } \\
\text { "feminicídio" } \\
\text { como base no } \\
\text { modelo } \\
\text { ecológico de } \\
\text { fatores de } \\
\text { violência. }\end{array}$ & $\begin{array}{l}\text {-Vida familiar } \\
\text { conturbada } \\
\text { (violências). } \\
\text {-A pobreza e o } \\
\text { desemprego. } \\
\text {-A falta de } \\
\text { legislação e de } \\
\text { serviços para as } \\
\text { mulheres em } \\
\text { situação } \\
\text { violência. } \\
\text {-A tolerância e a } \\
\text { legitimação } \\
\text { social } \\
\text { violência. } \\
\text {-O isolamento } \\
\text { das mulheres, } \\
\text { tanto da } \\
\text { comunidade } \\
\text { como da família, } \\
\text { e a impunidade } \\
\text { dos agressores, } \\
\text { contribuem para } \\
\text { a reprodução do } \\
\text { problema. } \\
\text {-Ambiente } \\
\text { econômico } \\
\text { social, às formas } \\
\text { de organização } \\
\text { da sociedade, às } \\
\text { normas } \\
\text { crenças culturais } \\
\text { que contribuem } \\
\text { para criar um } \\
\text { clima em que a } \\
\text { violência } \\
\text { incentivada ou } \\
\text { inibida. }\end{array}$ & $\begin{array}{l}\text { A presença de violência em famílias } \\
\text { de origem (1ํo ambiente familiar pai- } \\
\text { mãe) como em seu } 2^{\circ} \text { ambiente } \\
\text { familiar (mãe-padrasto) influenciador } \\
\text { para as crianças por serem expostas } \\
\text { a tais atitudes da família. Chegando } \\
\text { à adultez e à formação de sua própria } \\
\text { família, haverá a tendência de } \\
\text { reproduzir a violência por ser o } \\
\text { repertório comportamental aprendido } \\
\text { na infância e entendido como o } \\
\text { "normal" e aceitável. Dessa maneira } \\
\text { demonstra como isso influencia, } \\
\text { dentro do modelo ecológico da } \\
\text { violência (um modelo que afirma em } \\
\text { seu segundo plano ou nível que a } \\
\text { relação do indivíduo com seu } \\
\text { ambiente imediato, ou seja, as } \\
\text { relações mais próximas que ocorrem } \\
\text { na família de pertença, ou pessoas } \\
\text { que formam o grupo familiar e/ou } \\
\text { vivem em ambientes familiares } \\
\text { violentos, sofrendo agressões de } \\
\text { qualquer tipo ou testemunhando a } \\
\text { prática de atos de violência) a } \\
\text { predispor as pessoas a perpetuarem } \\
\text { tais atos na adolescência, juventude e } \\
\text { vida adulta. }\end{array}$ \\
\hline $\begin{array}{l}\text { Artigo } \\
5\end{array}$ & $\begin{array}{l}\text { GOMES } \\
(2018) .\end{array}$ & $\begin{array}{l}\text { Revisão } \\
\text { (Colômbia) }\end{array}$ & $\begin{array}{l}\text { Apresentar um } \\
\text { panorama da } \\
\text { produção } \\
\text { epistemológica } \\
\text { feminista } \\
\text { latino- } \\
\text { americana que } \\
\text { reconhece três } \\
\text { ênfases na } \\
\text { análise, } \\
\text { compreensão e } \\
\text { resposta para } \\
\text { os feminicídios. }\end{array}$ & $\begin{array}{l}\text {-Relações de } \\
\text { poder que } \\
\text { implicam } \\
\text { confiança, } \\
\text { autoridade e } \\
\text { subordinação } \\
\text { (chefia, relação } \\
\text { laboral e } \\
\text { docente), atual } \\
\text { ou pregressa. } \\
\text {-Violência sexual } \\
\text { e/ou estupro. } \\
\text {-Trabalhadora do } \\
\text { sexo. } \\
\text {-Violência } \\
\text { pregressa } \\
\text { (inclusive } \\
\text { ameaças) por } \\
\text { parte do autor do } \\
\text { crime. }\end{array}$ & $\begin{array}{l}\text { O feminicídio existe na realidade e é a } \\
\text { expressão letal que representa a } \\
\text { dimensão mais brutal da violência de } \\
\text { gênero praticada contra as mulheres. } \\
\text { Há que se insistir na necessidade de } \\
\text { reconhecimento das três vertentes do } \\
\text { debate, presentes na literatura } \\
\text { existente, que discorre sobre os } \\
\text { feminicídios. Falar das mortes } \\
\text { violentas de mulheres em sua } \\
\text { totalidade não é o mesmo que } \\
\text { analisar os assassinatos de mulheres, } \\
\text { bem como é muito diferente da } \\
\text { reivindicação de um tratamento penal } \\
\text { adequado. Cada uma dessas ênfases } \\
\text { revela uma compreensão do } \\
\text { fenômeno e um objetivo em questão, } \\
\text { seja denunciar um conjunto de } \\
\text { violações e violências sistemáticas, } \\
\text { conhecer as especificidades das }\end{array}$ \\
\hline
\end{tabular}




\begin{tabular}{|c|c|c|c|c|}
\hline & & & & $\begin{array}{lr}\text {-Sinais } & \text { de } \\
\text { misoginia e ódio } \\
\text { contra a vítima } \\
\text { mulher. } \\
-0 \\
\text { precedido crime } \\
\text { sequestro } \\
\text { cometido na } \\
\text { frente de filhos e } \\
\text { filhas da vítima. }\end{array}$ \\
\hline $\begin{array}{l}\text { Artigo } \\
6\end{array}$ & $\begin{array}{l}\text { LÓPEZ- } \\
\text { OSSORIO et } \\
\text { al (2018). }\end{array}$ & $\begin{array}{l}\text { Revisão } \\
\text { (Espanha) }\end{array}$ & $\begin{array}{l}\text { Descrever } \\
\text { problemas de } \\
\text { gênero e de } \\
\text { assimetria a } \\
\text { perspectiva de } \\
\text { violência e } \\
\text { descrição de } \\
\text { seus fatores de } \\
\text { risco. }\end{array}$ & $\begin{array}{l}\text {-Fatores Sociais } \\
\text { (posição } \\
\text { desigual } \\
\text { mulheres das } \\
\text { Pobreza . Uso } \\
\text { regulatório da } \\
\text { violência). } \\
\text {-Fatores } \\
\text { Comunitários } \\
\text { (aceitação das } \\
\text { normas / papéis } \\
\text { tradicionais de } \\
\text { gênero). } \\
\text {-Fatores } \\
\text { Relacionais } \\
\text { Familiares } \\
\text { homem } \\
\text { múltiplos } \\
\text { parceiros } \\
\text { sexuais } \\
\text { Insatisfação } \\
\text { conjugal). } \\
\text {-Fatores } \\
\text { Individuais } \\
\text { (baixa } \\
\text { escolaridade } \\
\text { Uso nocivo de } \\
\text { álcool / drogas . } \\
\text { Aceitação } \\
\text { violência). }\end{array}$ \\
\hline $\begin{array}{l}\text { Artigo } \\
7\end{array}$ & $\begin{array}{l}\text { PÉREZ } \\
\text { MANZANO } \\
\text { (2018). }\end{array}$ & $\begin{array}{l}\text { Revisão } \\
\text { (Espanha) }\end{array}$ & $\begin{array}{l}\text { Oferecer uma } \\
\text { interpretação } \\
\text { coerente e útil } \\
\text { do } \\
\text { comportamento } \\
\text { feminicida. }\end{array}$ & $\begin{array}{l}\text {-Desvalorização/ } \\
\text { discriminação do } \\
\text { casal ou ex- } \\
\text { parceiro. } \\
\text {-Misoginia/ ódio } \\
\text { às mulheres. } \\
\text {-Prazer, } \\
\text { ganância, raça, } \\
\text { religião, } \\
\text { orientação } \\
\text { sexual } \\
\text { identidade ou de } \\
\text { gênero. }\end{array}$ \\
\hline
\end{tabular}

-Sinais mulher.

$\begin{array}{lr}\text {-O } & \text { crime } \\ \text { precedido } & \text { de } \\ \text { sequestro } & \text { e } \\ \text { cometido } & \text { na }\end{array}$

frente de filhos e filhas da vítima.

À morte de uma mulher nas mãos de seu parceiro ou ex-companheiro, constitui um instrumento de dominação discriminatória, ou seja, violência exercida contra a mulher para manter ou restaurar relações desiguais de poder ou, simplesmente, reafirmar o sentido discriminatório de seu ato, negando à vítima seu direito à igualdade. Nessa perspectiva, o feminicídio do casal ou ex-parceiro é um crime de ódio, uma vez que o que é característico disso é sua dimensão coletiva e a condição paralela e dispensável da vítima. No feminicídio do companheiro ou ex-companheiro, a morte da mulher está relacionada 


\begin{tabular}{|c|c|c|c|c|}
\hline $\begin{array}{l}\text { Artigo } \\
8\end{array}$ & $\begin{array}{l}\text { MAIA } \\
\text { (2019). }\end{array}$ & $\begin{array}{l}\text { Revisão } \\
\text { (Brasil) }\end{array}$ & $\begin{array}{l}\text { Entender como } \\
\text { as } \\
\text { representações } \\
\text { de gênero } \\
\text { operam, como } \\
\text { são acionadas } \\
\text { nos discursos } \\
\text { que circulam } \\
\text { nos processos } \\
\text { e como elas } \\
\text { acabam a } \\
\text { constituindo a } \\
\text { base para a } \\
\text { atribuição das } \\
\text { penas. }\end{array}$ & $\begin{array}{l}\text {-Assassino } \\
\text { pertencer a } \\
\text { algum grupo de } \\
\text { gangue } \\
\text { facção. } \\
\text {-Maus-tratos que } \\
\text { a vítima sofria do } \\
\text { ex-companheiro. } \\
\text {-Violência } \\
\text { emocional. } \\
\text {-Provocações }\end{array}$ \\
\hline
\end{tabular}

$\begin{array}{lll}\text { Artigo } & \text { RUIZ- } & \text { Revisão } \\ 9 & \text { PÉREZ; } & \text { (Espanha) } \\ & \text { PASTOR- } & \\ & \text { MORENO } & \\ & \text { (2020). } & \end{array}$

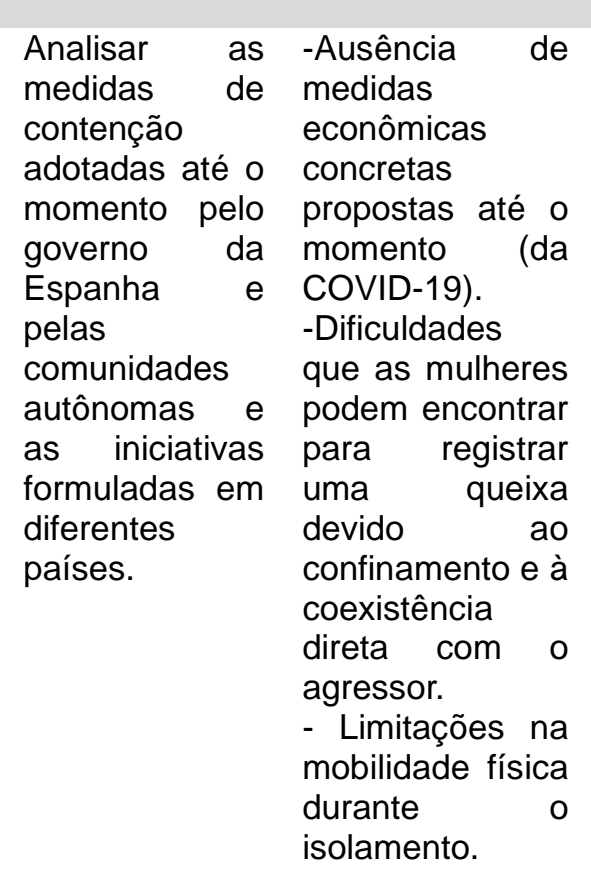

ao comportamento concreto preconcebido (machismo) e esperado da mulher concreta.

A tipificação do feminicídio e a fixação de penas mais elevadas para os feminicidas cumprem a importante função de chamar atenção, no âmbito da sociedade e no cotidiano das pessoas, para as relações assimétricas de poder historicamente instituídas que fundamentam esses crimes baseados em gênero. Mas, embora seja um dos países onde as mulheres mais morrem, o Brasil foi um dos últimos países na América Latina a criar uma lei específica sobre o feminicídio e o que determinou as penas mais brandas. Além disso, a aprovação do texto final da lei indica um retrocesso em relação aos estudos e às discussões em torno desses crimes. A lei do feminicídio foi uma resposta do Estado às pressões feministas e uma tentativa de proteger as mulheres, em um momento de ampliação e de reconhecimento de seus direitos no Brasil. Ela tem sido fundamental para nomear, reconhecer e dar visibilidade à violência de gênero, por séculos naturalizada e silenciada. Entretanto o poder de disciplina, de coerção e de punição não é suficiente para mudar comportamentos e valores.

À medida que mais países implementaram medidas de contenção, foram relatados aumentos preocupantes. As linhas de ajuda registraram um aumento de $91 \%$ na Colômbia, $60 \%$ no México, $40 \%$ na Austrália, 30\% em Chipre e 20\% nos Estados Unidos. Na Espanha, chama o 016 (telefone de informações e conselhos sobre violência de gênero) aumentaram $10,5 \%$ e as consultas online $182,93 \%$ em relação a março do ano anterior. Como resultado da declaração de estado de alarme e confinamento, novas medidas foram adotadas para aliviar o possível impacto da violência de gênero. Dois dias após o início da quarentena, o Ministério da Igualdade aprovou um Plano de Contingência contra a violência de gênero diante da crise do coronavírus. Esse plano inclui várias medidas necessárias para adaptar e garantir o bom funcionamento dos 


serviços voltados à proteção das
vítimas de violência de gênero nas
atuais circunstâncias excepcionais.
Em 31 de março, o conselho de
ministros aprovou um Decreto-Lei
Real de medidas urgentes para
proteger e ajudar vítimas de violência
masculina durante a crise da COVID-
19 .

\section{CATEGORIAS DE ANÁLISE}

A partir da análise dos artigos foram formuladas duas categorias de análises relacionadas com a pesquisa, sendo na primeira relacionada com "fatores que motivam as pessoas a praticarem o feminicídio" e a segunda referente a "legislação e regulamentação do crime do feminicídio" que seguidamente descrevemos.

\section{O que motiva as pessoas a praticarem o feminicídio}

Nesta categoria se descreve os fatores de risco e/ou situações que motivam os infratores a cometerem o feminicídio. Entre vários fatores, os estudos destacam a situação socioeconómica desfavorável, relação de poder, controle e dominação de homens sobre as mulheres, falta de legislação e serviços disponíveis para as mulheres em situação de violência, a tolerância e a legitimação social da violência entre outros fatores.

O artigo 1, por exemplo, apresenta como fatores que impulsionam a prática de feminicídio, violência recorrente contra mulher (doméstica, sexual, física, psicológica, econômica e patrimonial, estrutural e institucional), relação de subordinação e dominação, ciúmes e discriminação contra mulher, objetificação do corpo e vida da mulher e a impunidade gerada pelo Estado (VANEGAS, 2015). No artigo 2, as situações associadas com a prática do feminicídio incluem a tolerância social em relação à violência contra as mulheres, a impunidade praticamente generalizada, falta de vontade política para enfrentar específica e adequadamente a violência contra as mulheres, supremacia masculina, ato passional (esposo, ex-esposo, namorado e relacionamento casal conturbado), poder, controle e dominação de homens sobre mulheres e a violência sexual (ALBARRAN, 2015).

Enquanto no artigo 3 se apresenta como fatores de risco ao feminicídio a ameaça a dignidade da mulher, a prática de extermínio seletivo, desaparecimento ou rapto com tortura, 
violação sexual, quase sempre seguida de morte de mulheres jovens, trabalhadoras e pobres, submissão, escravidão, exploração sexual, mutilação sexual e a violência associadas a contextos generalizados de ódio e de discriminação sobre as mulheres (SOUSA, 2016). No entanto, os fatores que vulnerabilizam as mulheres, como se apresenta no artigo 4, estão relacionados com a vida familiar conturbada (de violências), a pobreza e o desemprego, falta de legislação e serviços para as mulheres em situação de violência, a tolerância e a legitimação social da violência, o isolamento das mulheres, tanto da comunidade, como da família, e a impunidade dos agressores (OLIDEN; VELÁSQUEZ, 2017).

O artigo 5, por sua vez, levanta a questão de relações de poder, autoridade e subordinação que os homens se colocam em ambientes laborais, violência sexual e/ou estupro, violência pregressa (inclusive ameaças) por parte do autor do crime, sinais de misoginia e ódio contra a vítima mulher e crime precedido de sequestro (GOMES, 2018).

O artigo 6 discrimina os fatores de riscos em sociais (posição desigual das mulheres, a pobreza e o uso regulatório da violência); comunitários (aceitação das normas e/ou papéis tradicionais de gênero, uso regulatório da violência e o afrouxamento das sanções comunitárias), fatores relacionais e familiares (o homem tendo múltiplos parceiros sexuais, insatisfação conjugal, nível educacional baixo ou diferente) e, ainda, fatores individuais (baixa escolaridade, uso nocivo de álcool e/ou drogas e a aceitação da violência) (LÓPEZ-OSSORIO et al, 2018). O artigo 7 apresenta como fatores a desvalorização/ discriminação do casal ou exparceiro, misoginia/ódio às mulheres e prazer, ganância, raça, religião, orientação sexual ou identidade de gênero (PÉREZ MANZANO, 2018).

No artigo 8 fala de o infrator pertencer a algum grupo de gangue ou facção, os maustratos que a vítima sofria do ex-companheiro, violência emocional, provocações entre parceiros ou com ex-parceiro, crimes passionais e uso de drogas e a prática de prostituição (MAIA, 2019). E, finalmente, o artigo 9 é o único estudo que fala sobre os fatores associados à prática do feminicídio durante a pandemia da COVID-19 e destaca a ausência de medidas econômicas concretas propostas até esse momento do isolamento, dificuldades que as mulheres podem encontrar para registrar uma queixa, devido ao confinamento e à coexistência direta com o agressor e limitações na mobilidade física durante esse período (RUIZ-PÉREZ; PASTORMORENO, 2020).

\section{Legislação e regulamentação do crime do feminicídio}


Nesta categoria apresentam-se as estratégias governamentais adotadas para responder ao crime do feminicídio. Dos estudos analisados, dois foram desenvolvidos na Colômbia (artigo 1 e artigo 5), um na Venezuela (artigo 2), dois no Brasil (artigo 3 e artigo 8), um na Bolívia (artigo 4) e três na Espanha (artigo 5, artigo 6 e artigo 9). Assim, neste panorama que geograficamente é discutido o fenômeno nos leva a perceber os impactos e as estratégias a serem adotadas. Desde os anos da década 2000, considerando a incidência e a gravidade dos feminicídios, o alto grau de impunidade destes crimes e a pressão social dos movimentos feministas e de mulheres, alguns estados passaram a responder penalmente ao problema. Dessa forma, até 2015, muitos países da América Latina realizaram algumas modificações em seus Códigos Penais, para enquadrar o feminicídio: Costa Rica (2007), Guatemala (2008), Chile (2010), Peru (2011), El Salvador (2012), México (2012) e Nicarágua (2012); sendo o Brasil e Colômbia no mesmo ano (2015) e (GOMES, 2018).

$\mathrm{Na}$ Colômbia, como se descreve no artigo 1 e artigo 5, o feminicídio foi considerado crime atentado a saúde pública pelo artigo 26 da Lei 1257 de 2008, mas somente em 2015 que o Supremo Tribunal de Justiça emitiu a sentença que lançou as bases para o entendimento da conduta e para configurá-la com toda a seriedade. Durante muito tempo, houve diversos avanços para uma verdadeira igualdade entre homens e mulheres, mas ainda há um longo caminho a percorrer para eliminar a violência e a discriminação (VANEGAS, 2015; GOMES, 2018).

Segundo o artigo 2 embora a Venezuela tenha assinado vários acordos e convenções relacionados à questão da violência contra as mulheres, tais como: a Convenção Interamericana para Prevenir, Punir e Erradicar a Violência contra as Mulheres (Belém do Pará, 1994) ou a Plataforma de Ação Para o avanço da mulher (Pequim, 1995), é em 2007 que a Lei Orgânica do Direito da Mulher a uma vida livre de Violência é redigida e promulgada. Nesta lei, revela-se que esse tipo de crime deve ser objeto de considerações prioritárias nas políticas públicas. Isso marcou um avanço significativo no reconhecimento e visibilidade da violência contra as mulheres e sua abordagem legal no país. No entanto, é decisivo destacar que o construto femicídio (termo equivalente a feminicídio utilizado pela autora) foi registrado na reforma deste instrumento legal em 25 de novembro de 2014: femicídio é a forma extrema de violência de gênero, causada pelo ódio ou desprezo por sua condição de mulher, que degenera em sua morte, produzida tanto na esfera pública quanto na privada (ALBARRAN, 2015). 
No Brasil, a taxa de homicídios de mulheres aumentou significativamente a partir de 2007 o que levou o poder público a sancionar pela Lei 13 104/2015 (em março de 2015), a Lei do Feminicídio (mesmo apesar da entrada em vigor da Lei Maria da Penha, em 2006), classificando-o como crime hediondo e com agravantes quando acontece em situações específicas de vulnerabilidade: gravidez, menor de idade, na presença de filhos, entre outras (SOUSA, 2016). Entretanto segundo MAIA (2019, p.4) a tipificação do feminicídio no Brasil é recente (2015, sancionada pela presidenta Dilma a lei 13.104), mas em termos históricos as razões do feminicídio já estavam enraizadas na cultura e legitimadas no passado por outro ordenamento jurídico; o Código Filipino 4 (1603), que assegurava o poder soberano do marido sobre a vida de sua esposa que no o artigo 25: "[...] toda mulher que fizer adultério a seu marido, morra por isso[...]".

No que se refere à Bolívia, o artigo 4 destaca que os casos de feminicídios começaram a ser tipificados como crime pela lei no 348/2013 em seu artigo 7, onde define mais especificamente os tipos de violência contra as mulheres nas formas de violência física, psicológica, sexual e econômica: (1) Violência física sendo uma ação que causa lesões e/ou danos corporais, internos, externos ou ambos, temporários ou permanentes, que se manifesta imediatamente ou a longo prazo, utilizando ou não força física, armas ou qualquer outro meio. (2) Violência feminicida, a ação de extrema violência que viola o direito fundamental à vida e causa a morte de mulheres pelo fato de ser. E (3) Violência psicológica, o conjunto de ações sistemáticas de desvalorização, intimidação e controle do comportamento e decisões das mulheres, que têm como consequência a diminuição da autoestima, depressão, instabilidade psicológica, desorientação e até suicídio (OLIDEN; VELÁSQUEZ, 2017, p.199)

A situação de Espanha é descrita nos artigos 6, 7 e 9. A luta contra a violência por parceiros íntimos é uma questão de Estado há muitos anos. Sua forma mais grave é o homicídio, embora tenha taxas muito baixas em comparação com outros países vizinhos e a tendência tenha caído nos últimos anos. Em relação ao feminicídio, o legislador optou por não individualizá-lo como crime específico, o Código Penal Espanhol identifica o início do ciclo de violência, maus tratos, ameaças ou coerção leve e o ataque à integridade moral habitual (artigos 153.1, 171, 172, 173.2). O Tribunal Constitucional espanhol se referiu a esse elemento

\footnotetext{
${ }^{4}$ É uma compilação jurídica que resultou da reforma do código manuelino, por Filipe II de Espanha (Felipe I de Portugal), durante o domínio castelhano. No Brasil, país que havia se separado de Portugal em 1822, vigeu em matéria civil até 1916, quando foi revogado pelo Código Civil brasileiro de 1916, assim as Ordenações Filipinas tiveram uma sobrevida de quase cinco décadas no Brasil mesmo após estas terem sido revogadas em Portugal.
} 
na Sentença 59/2008 e serviu para substanciar que o artigo 153.1 do Código Penal espanhol, que sanciona os leves maus-tratos de homens em relação a seu parceiro ou ex-esposa, é uma regra legítima que sanciona mais severamente os maus tratos às mulheres, porque constitui um tipo de violência expressiva de discriminação exercida sobre as mulheres. Por esse motivo, é um ato criminoso que reflete uma maior desvalorização dos injustos (PÉREZ MANZANO, 2018).

No entanto, o artigo 9 descreve detalhadamente as estratégias de enfrentamento ao feminicídio durante a pandemia da COVID-19, considerando as crises, emergências e tempos de agitação associados a um aumento da violência interpessoal, incluindo a violência contra as mulheres. Como resultado da declaração de estado de alarme e confinamento, foram adotadas novas medidas para aliviar o possível impacto da violência de gênero (Plano de Contingência Contra Violência de Gênero em face da crise do coronavírus ou Decreto-Lei Real sobre medidas urgentes). Este documento analisa as medidas de contenção adotadas até o momento pelo governo da Espanha, pelas comunidades autônomas e as iniciativas formuladas em diferentes países (RUIZ-PÉREZ; PASTOR-MORENO, 2020).

As medidas adotadas até agora pelo governo da Espanha são:

(1) a declaração de serviço essencial de assistência abrangente às vítimas de violência de gênero, garantindo o funcionamento normal dos dispositivos de informação durante 24 horas, resposta à emergências e acolhimento de mulheres em risco e assistência psicológica, legal e social pessoalmente (por telefone ou através de outros canais). (2) Ativação de um novo recurso de emergência para mulheres em situação de violência de gênero por meio de uma mensagem de alerta por mensagem instantânea com geolocalização que será recebida pelas Forças e Órgãos de Segurança do Estado. (3) Campanha institucional para aumentar a conscientização contra a violência de gênero durante o período de confinamento. Existem duas linhas de materiais: uma voltada para as vítimas, com o slogan "Estamos com você, paramos a violência de gênero juntos", com o objetivo de informar sobre os serviços disponíveis e ampliados no contexto do COVID-19 e outra voltada para envolver a sociedade na denúncia da violência e no apoio às mulheres necessitadas, com o slogan "Paramos a violência de gênero juntos, estamos com você". (4) Preparação de um guia de ação para mulheres que sofrem violência de gênero em uma situação de residência permanente derivada do estado de alarme pelo COVID-19. Ele coleta informações sobre os recursos disponíveis e diretrizes de ação específicas com base na situação pessoal das mulheres. (5) Atendimento psicológico imediato via WhatsApp, através dos telefones fornecidos pelo Ministério da Igualdade. (6) Utilização de estabelecimentos turísticos, caso não haja locais disponíveis durante o estado de alarme nos centros designados para isso e é necessário garantir a segurança das vítimas. (7) A inclusão do "Botão SOS" no aplicativo AlertCops, que permite que o pessoal da saúde e as vítimas de violência de gênero exijam discretamente a assistência imediata das Forças de Segurança do Estado (RUIZPÉREZ; PASTOR-MORENO, 2020 p. 2). 


\section{DISCUSSÃO}

Falar do feminicídio no período da pandemia da COVID-19 é trazer discussões sobre direitos de igualdade, de dignidade da mulher e da pessoa humana. É lutar contra a violência doméstica e atos aversivos ao gênero como, por exemplo, a misoginia, menosprezo pela condição feminina ou discriminação de gênero. Por isso a importância de tipificá-lo, porque é uma forma de reconhecê-lo como lei que defende as mulheres que estão sendo mortas pela razão de serem mulheres, expondo a fratura da desigualdade de gênero que persiste em nossa sociedade. E é social, por combater a impunidade, evitando que feminicidas sejam beneficiados por interpretações jurídicas anacrônicas e moralmente inaceitáveis, como a falsa ideia desse fenômeno ser um "crime passional" (ROMIO, 2017).

Assiste-se cada dia notícias de violência doméstica, agressão sexual e sequestros acompanhados por mortes de mulheres pela condição de gênero. Isso associa-se ao poder e dominação que alguns homens detém sobre as mulheres e a tolerância e/ou a legitimação social da violência em alguns contextos. Nestas situações as vítimas ou pessoas com informação do risco que certas mulheres estão podem entrar em contato e denunciar na Rede de Atendimento a Mulheres em Situação de Violência a partir dos números "100 ou 180". Esta estratégia tem prevenido casos de violência contra mulher que poderiam ter terminado em feminicídio.

Os estudos em análise apontam a fragilidade dos governos na implementação da lei contra o feminicídio e a impunidade dos infratores durante longo tempo. Por isso, em muitos países da América Latina, as leis contra o feminicídio foram adaptadas para responder às violações e desrespeito dos direitos humanos e da mulher, mesmo com leis contra a violência da mulher já existente, como é o caso da Lei no 11.340, de 7 de agosto de 2006 (Lei Maria da Penha dos Juizados de Violência Doméstica e Familiar contra a Mulher) que ajudou na reformulação da Lei n 13.104, de 2015 do Código Penal brasileiro sobre o feminicídio. No entanto, estes decretos e outras estratégias devem ser divulgados e implementados para garantir a execução dos direitos humanos e proteção das mulheres.

Com a pandemia da COVID-19 os casos de violência doméstica contra mulher e, consequentemente, do feminicídio registrou um aumento considerável; isto porque todos os membros das famílias começaram a passar mais tempo juntos. A situação atual impede às vítimas a chance de pedir ajuda, encontrar familiares, amigos ou mesmo buscar apoio nas 
situações em que é necessário, como se descreve num relatório do Fórum Brasileiro de Segurança Pública que, entre março e abril, os casos de feminicídios aumentaram 22,2\% em 12 estados, comparativamente ao mesmo período do ano passado (AGÊNCIA BRASIL, 2020).

Apesar da falta de estudos publicados nos últimos meses sobre o feminicídio durante a pandemia da COVID-19, muitas reportagens de mídias e órgãos de informação (TV, Rádio, Jornais, etc) tem apresentado índices elevados durante pandemia em comparação com os anos anteriores. Isso deve-se a vários fatores como convivência mais próxima dos agressores e das vítimas, que, no novo contexto, podem mais facilmente impedi-las de se dirigir a uma delegacia ou a outros locais que prestam socorro às vítimas, como centros de referência especializados, ou, inclusive, de acessar canais alternativos de denúncia, como telefone ou aplicativos. Um estudo recente feito pelo Fórum Brasileiro de Segurança Pública destaca a variação de números e porcentagens de casos, entre 2019 e 2020, em alguns estados como Acre, Mato Grosso, Pará, Rio Grande do Norte, Rio Grande do Sul e São Paulo sendo este último com índices superelevados como se descreve na Tabela 2.

Tabela 2: Homicídios de Mulheres e Feminicídios

\begin{tabular}{|c|c|c|c|c|c|c|c|c|}
\hline \multirow[t]{2}{*}{ UF } & \multicolumn{3}{|c|}{ Homicídios de mulheres } & \multicolumn{3}{|c|}{ Feminicídios } & \multicolumn{2}{|c|}{\begin{tabular}{|l|} 
Proporção de \\
feminicídios \\
em relaçāo aos \\
homicídios (em \%)
\end{tabular}} \\
\hline & $\mathrm{mar} / 19$ & $\mathrm{mar} / 20$ & Variação (\%) & $\mathrm{mar} / 19$ & $\mathrm{mar} / 20$ & $\begin{array}{l}\text { Variação } \\
\text { (\%) }\end{array}$ & $\mathrm{mar} / 19$ & $\mathrm{mar} / 20$ \\
\hline Acre & 3 & 2 & $-33,3$ & 1 & 2 & 100,0 & 33,3 & 100,0 \\
\hline Mato Grosso & $\ldots$ & $\ldots$ & $\ldots$ & 2 & 10 & $400 \%$ & $\ldots$ & $\ldots$ \\
\hline Pará & 22 & 21 & $-4,5$ & 4 & 4 & 0,0 & 18,0 & 19,0 \\
\hline Rio Grande do Norte & 7 & 7 & 0,0 & 1 & 4 & 300,0 & 14,3 & 57,1 \\
\hline Rio Grande do Sul & $\ldots$ & $\ldots$ & $\ldots$ & 11 & 11 & 0,0 & $\ldots$ & $\ldots$ \\
\hline São Paulo & 38 & 41 & 7,9 & 13 & 19 & 46,2 & 34,2 & 43,2 \\
\hline
\end{tabular}

Como se pode ver, no Acre, os índices de feminicídios no consolidado do trimestre mostra crescimento de $33 \%$. No $1^{\circ}$ trimestre do ano passado foram 3 feminicídios e no $1^{\circ}$ trimestre de 2020 foram 4 mortes. No Mato Grosso os feminicídios dobraram e foram de 11 no $1^{\circ}$ trimestre de 2019 para 22 no $1^{\circ}$ deste ano. No Pará, os homicídios de mulheres cresceram $11,8 \%$ e os feminicídios $187,5 \%$. No Rio Grande do Sul, se compararmos os dados do primeiro trimestre deste ano com o do ano passado verificamos crescimento de $73 \%$, saltando de 15 
casos no $1^{\circ}$ trimestre de 2019 para 26 no $1^{\circ}$ trimestre de 2020 . Em São Paulo o crescimento é também bastante acentuado. No primeiro trimestre de 2019 foram 39 vítimas de feminicídio em comparação com 49 neste ano durante o mesmo período, havendo um crescimento de $25 \%$ (BRASIL, 2020).

\section{CONSIDERAÇÕES FINAIS}

O assassinato de mulheres em situações de desigualdade de gênero e sua condição (feminicídio) é um crime hediondo condenável no sistema jurídico nacional e internacional. No Brasil, casos de feminicídios são reportados quase diariamente. São mulheres vítimas de atos macabros dos seus ex-companheiros, esposos ou pessoas conhecidas por acharem ter 0 domínio e o poder contra aquelas. Muitas vezes, esta prática é antecedida por violências recorrentes como a doméstica, a sexual, a física, a psicológica, dentre outras associadas à relação de subordinação e dominação, ciúmes e discriminação, situações que deveriam ser ultrapassadas, se esses atos fossem denunciados.

Este não é um fenômeno recente. Esses crimes vêm sendo praticados e é visto um aumento de incidência a cada ano que passa. Nos anos 2000, observou-se a incidência, a gravidade de assassinatos de mulheres e os altos graus de impunidade dos infratores. Com 0 isolamento devido a pandemia da COVID-19 e a impossibilidade das mulheres (vítimas) saírem de casa (encontrar ajuda ou se afastar dos agressores) a vulnerabilidade é maior. Fala-se de alguns estados brasileiros, como Rio de Janeiro e Minas Gerais com índices elevados nos primeiros meses da pandemia (março e abril).

A situação atual da pandemia da COVID-19 faz com que os fatores, como dificuldades de registrar queixas devido ao confinamento e à coexistência direta com o agressor e as limitações na mobilidade física durante o isolamento, vulnerabilizam as mulheres. Ainda, devido ao medo de exposição e retalhação, muitas mulheres não denunciam mesmo depois de sofrer vários episódios de violência. Para tal, sugere-se a divulgação das medidas de proteção às mulheres e respectivos canais de busca de ajuda e atendimento gratuito (100 ou 180) para facilitar que os infratores sejam identificados e punidos.

Apesar de o estudo ter proporcionado algumas contribuições para fomentar políticas públicas voltadas aos direitos humanos, algumas limitações foram identificadas, como o fato de a revisão contemplar poucas bases com artigos que abordam especificamente a violência no período de isolamento da COVID-19 (talvez por ser uma temática muito recente e pouco 
explorado). No entanto, destaca-se a pertinência da pesquisa por promover os direitos humanos e a saúde da mulher sugerindo-se assim mais pesquisas voltadas a este assunto.

\section{REFERÊNCIAS}

AGÊNCIA BRASIL, Direitos Humanos. Casos de feminicídio crescem $22 \%$ em 12 estados durante a pandemia. Agência Brasil, Publicado em 01/06/2020-14:34PorLetyciaBondRepórterdaAgênciaBrasil- $\quad$ São $\quad$ Paulo, $2020 . \quad$ Disponível em:https://agenciabrasil.ebc.com.br/direitos-humanos/noticia/2020-06/casos-de-feminicidiocrescem-22-em-12-estados-durante-pandemia; acesso no 25 de junho de 2020.

AGÊNCIA BRASIL, Direitos Humanos. Sete em cada 10 vítimas de feminicídio em SP foram mortas em casa. Agência Brasil, Publicado em 13/04/2020-21:51PorCamilaBoehmRepórterdaAgênciaBrasil- São Paulo, $2020 . \quad$ Disponível em: https://agenciabrasil.ebc.com.br/direitos-humanos/noticia/2020-04/sete-em-cada-10-vitimas-defeminicidio-em-sp-foram-mortas-em-casa; acesso no 25 de junho de 2020.

ALBARRAN, Jenny. Referentes conceptuales sobre femicidio / feminicidio: Su incorporación en la normativa jurídica Venezolana. Comunidad y Salud [online]. 2015, vol.13, n.2, pp. 75-80. ISSN 1690-3293

BRASIL, ARTIGO19. Dados sobre feminicídio no Brasil. Defendendo a Liberdade de Expressão e Informação, Rua João Adolfo, 118, conjunto 802 CEP 01050-020 | Centro | São Paulo | $\quad$ SP, 2018. Disponível em: https://artigo19.org/wpcontent/blogs.dir/24/files/2018/03/Dados-Sobre-Feminic\%C3\%ADdio-no-Brasil-.pdf; acesso no 25 de junho de 2020.

BRASIL, Fórum Brasileiro de Segurança Pública; Decode. Violência doméstica durante a pandemia de Covid-19. Brasil, 2020. Disponível em: https://forumseguranca.org.br/wpcontent/uploads/2018/05/violencia-domestica-covid-19-v3.pdf, acesso no 09 de julho de 2020.

BRASIL, Instituto de Pesquisa Econômica Aplicada -IPEA; Fórum Brasileiro de Segurança Pública- FBSP. Atlas de violência. Brasília: Rio de Janeiro: São Paulo: Instituto de Pesquisa Econômica Aplicada; Fórum Brasileiro de Segurança Pública. ISBN 978-85-67450-14-8, 2019. Disponível em: https://www.ipea.gov.br/atlasviolencia/download/19/atlas-da-violencia-2019; acesso no 25 de junho de 2020.

BRASIL, Secretaria-Geral, Subchefia para Assuntos Jurídicos. LEI № 13.104, DE 9 DE MARÇO DE 2015. Brasília, 9 de março de 2015; 194ํ da Independência e $127^{\circ}$ da República. Disponível em: http://www.planalto.gov.br/ccivil 03/ ato2015-2018/2015/lei//13104.htm; acesso no 25 de junho de 2020.

GOMES, Izabel Solyszko. Feminicídios: um longo debate. Revista Estudos Feministas, 26(2)2018. doi:10.1590/1806-9584-2018v26n239651 
LEITE, Catalina. Países registram aumento de violência doméstica durante período de quarentena; veja como denunciar casos no Ceará. O Povo Online 2020; Disponível em: https://www.opovo.com.br/coronavirus/2020/03/30/paises-registram-aumento-de-violenciadomestica-durante-periodo-de-quarentena--veja-como-denunciar-casos-no-ceara.html; acesso no 25 de junho de 2020.

LÓPEZ-OSSORIO, Juan José; CARBAJOSA, Pablo; CEREZO-DOMÍNGUEZ, Ana Isabel; GONZÁLEZ-ÁLVAREZ, José Luis; LOINAZ, Ismael; MUÑOZ-VICENTE, José Manuel. Taxonomía de los homicidios de mujeres en las relaciones de pareja. Psychosocial Intervention, 27 , 95-104, 2018. https://doi.org/10.5093/pi2018a11

MAIA, Cláudia. Sobre o (des)valor da vida: feminicídio e biopolítica. História [online]. 2019, vol.38, e2019052. Epub Dec 02, 2019. ISSN 1980-4369. http://dx.doi.org/10.1590/19804369e2019052.

MARANHÃO, Romero de Albuquerque. A violência doméstica durante a quarentena da COVID-19: entre romances, feminicídios e prevenção; Braz. J. Hea. Rev., Curitiba, v. 3, n. 2, p.3197-3211 mar./apr. 2020. ISSN 2595-6825. DOl:10.34119/bjhrv3n2-161

OLIDEN, Norman; VELÁSQUEZ, Carlos. Historia familiar y características de personalidad de un feminicida. Revista Ajayu de Psicología, Vol. 15, No. 2: 195 - 213 (Agosto 2017) ISSN 2077-2161

PÉREZ MANZANO, Mercedes. La caracterización del feminicidio de la pareja o expareja y los delitos de odio discriminatorio. Derecho PUCP, (81), 163-196, 2018. https://doi.org/10.18800/derechopucp.201802.006

ROMIO, Jackeline. A mortalidade feminina por feminicídios. ComCiência, Revista Electronica de Jornalismo Científico, Dossiê Violência (out-2017)_comciência, Artigo,Dossiê192, Disponível em: http://www.comciencia.br/a-mortalidade-feminina-por-feminicidios/; acesso no 25 de junho de 2020.

ROMIO, Jackeline Aparecida Ferreira. Feminicídios no Brasil, uma proposta de análise com dados do setor de saúde. Campinas, SP:[s.n.], 2017. Disponível em: http://repositorio.unicamp.br/jspui/bitstream/REPOSIP/330347/1/Romio JackelineAparecidaFer reira D.pdf; acesso no 25 de junho de 2020.

RUIZ-PÉREZ, Isabel; PASTOR-MORENO, Guadalupe. Medidas de contención de la violencia de género durante la pandemia de COVID-19. Gaceta Sanitaria. doi:10.1016/j.gaceta.2020.04.005.

SOUSA, Tânia Teixeira Lake de. Feminicídio: uma leitura a partir da perspectiva feminista. Ex

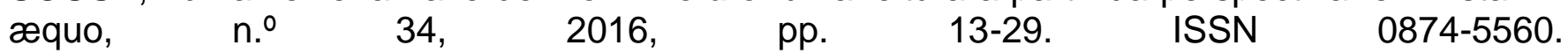
http://dx.doi.org/https://doi.org/10.22355/exaequo.2016.34.02

VANEGAS, Farid Samir Benavides. Feminicidio y derecho penal. Revista Criminalidad, 2015, vol.57, n.1, pp.75-90. ISSN 1794-3108. 